\title{
Rotunda de Ribeirão Vermelho: exemplo emblemático do Patrimônio Ferroviário Brasileiro
}

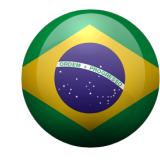

\section{Ronaldo André Rodrigues da Silva}

Doutor em História (U.Minho); Mestre em Administração (UFMG); Master em Conservação e Restauração do Patrimônio Arquitetônico Urbano (ETSAM/UCM); Bacharel em Engenharia Elétrica (PUC-MG); Administração (UFMG). Professor da P. U. C. Minas Gerais. Belo Horizonte [MG] Brasil. <ronaldoandre@gmail.com>

\begin{abstract}
Resumo
A importância dos complexos ferroviários para a história brasileira compõe-se a partir do desenvolvimento econômico-industrial de meados do século XIX. Constitui-se também uma relação entre a realidade históricosocial das cidades brasileiras e os complexos ferroviários por meio do desenvolvimento de sistemas sociais ou de infraestrutura de cidades e regiões. Dentre as estruturas ferroviárias, destacam-se as rotundas ferroviárias, não somente por sua importância para os complexos ferroviários e manutenção das máquinas, mas pela grandiosidade e identidade arquitetônica. Elas, comumente, constituíram-se como um dos principais edifícios e sempre despertaram interesse, desde sua centralidade nas oficinas à admiração das pessoas por seu tamanho, estrutura e complexidade o que as caracterizaria como elementos emblemáticos. A partir dessas ideias, o trabalho busca apresentar a realidade de um desses exemplares, a rotunda ferroviária de Ribeirão Vermelho, localizada na cidade homônima em Minas Gerais (Brasil). Propõe-se uma reflexão a partir do exemplo e da realidade dessa estrutura ferroviária que reflete, em grande parte, o complexo conjunto de elementos ferroviários no Brasil. Há aquelas que mantêm as suas funções, foram restauradas ou reutilizadas, mas também outras que foram transformadas em equipamentos sociais, e, negativamente, as abandonadas. Ao final, avaliamse os diversos exemplos de rotundas ferroviárias, desde a reutilização e reconversão ao abandono e arruinamento. Por fim, a reflexão sobre a arquitetura ferroviária, seu aspecto singular e emblemático e sua importância para a memória e a história devem ser entendidos de acordo com as múltiplas e interdisciplinares interpretações acerca do patrimônio cultural e industrial e da memória histórica e social.
\end{abstract}

\section{Palavras-chave}

Rotundas ferroviárias. Patrimônio Ferroviário. Patrimônio Industrial. Ribeirão Vermelho. Objetos emblemáticos.

\section{The "Ribeirão Vermelho" roundabout: emblematic example of Brazilian Railway Heritage}

\begin{abstract}
The importance of railway complexes for Brazilian history is built on the economic-industrial development of the mid-19th century. It is also a relationship between the historical-social reality of Brazilian cities and the railway complexes through the development of social systems or infrastructure of cities and regions. Among the railway structures, the railway roundabouts stand out, not only because of their importance to railroad complexes and maintenance of the machines, but also because of the architectural grandeur and identity. They have commonly constituted one of the main buildings and have always aroused interest, from their centrality in the railway offices to the admiration of people for their size, structure and complexity, which would characterize them as emblematic objects. Based on these ideas, the paper seeks to present the reality of one of these examples, the Ribeirão Vermelho railway roundhouse, located in the namesake city in Minas Gerais (Brazil). It is proposed a reflection based on the example and reality of this railway structure that largely reflects the complex set of railway elements in Brazil. There are those who maintain their functions, have been restored or reused, but also others that have been transformed into social equipment, and, negatively, abandoned ones. At the end, we evaluate the various examples of railway roundhouses, from reuse and reconversion to abandonment and ruin. Finally, the reflection on the railway architecture, its unique and emblematic aspect and its importance for memory and history must be understood according to the multiple and interdisciplinary interpretations about cultural and industrial heritage and historical and social memory.
\end{abstract}

\section{Keywords}

Railway Roundhouse. Railway Heritage. Industrial Heritage. Ribeirão Vermelho. Emblematic Objects. 


\section{Introdução}

A categorização de objetos emblemáticos reporta à observação e análise de um processo de apropriação de signos e significados os quais determinam todo um significado o qual determina uma contrapartida de identificação e identidade com um grupo de indivíduos ou mesmo sociedade. Essas relações estão colocadas nos objetos museais e na própria instituição do campo museológico desde suas origens aos dias de hoje. Uma reinterpretação dessas relações para além das instituições museológicas, para objetos musealizados, mesmo que em meio à sociedade ou comunidade redefine as relações e propõe olhares para a questão de signos e significados museológicos em determinadas situações e objetos que se constituem em elementos de identidade, identificação, memoria e cultura.

A partir dessas inter-relações se busca avaliar um exemplar único do conjunto patrimonial ferroviário, as rotundas, como objeto de admiração, identificação e identidade, mas igualmente de abandono e descaso. A situação de ambiguidade, de particularidade e de singularidade, que os tornam visíveis, também se define como elementos de esquecimento e de ruptura de relações, definindo-os como elementos invisíveis.

A ideia então é buscar a identificação desse objeto - a rotunda ferroviária - como elemento identitários de uma comunidade, de uma sociedade e seus indivíduos, caso particular de Ribeirão Vermelho (Minas Gerais, Brasil), mas também de preocupação e de necessidade de valorização urgente sob a possibilidade futura de desaparecimento de um exemplar onírico e emblemático para a comunidade local, a comunidade ferroviária e a história social e econômica do Brasil.

\section{Os objetos emblemáticos}

O conceito de objetos emblemáticos, a partir dos elementos apresentados por Bergeron (2015), circunscrevem igualmente aqueles objetos que se encontram musealizados, assim como objetos patrimonializados. Entretanto, as duas categorizações partem de uma construção de significados inerentes aos objetos as quais compreendem uma identidade em relação a indivíduos ou grupos, e mesmo sociedade os quais encontram certa identificação e identidade a tais objetos, ou seja, os objetos emblemáticos podem ser considerados, no contexto museológico, como itens ícones dos museus os quais se revelam como "objetos de pretextos" determinantes para se compreender histórias e memórias.

Complementa-se a categorização determinada por Charpentier (2016), em que se observa para além do discurso científico, formal e de investigação científica, a ideia de uma relação constituída entre indivíduo e objeto a qual se determina por um conjunto de elementos que determinam a função simbólica do objeto cuja estruturação se faz a partir de uma subjetividade do discurso e sua consequente descrição acerca do próprio objeto.

Torna-se necessário pontuar, acerca da categoria emblemático, uma relação de significância do objeto parte de uma funcionalidade e utilidade latentes as quais são transferidas para um contexto de signos e de significados que compreendem não somente a forma e o conteúdo do objeto, mas que se constitui uma relação com o indivíduo em que ocorre certo diálogo a partir das linguagens próprias àqueles objetos denominados semióforos. Tem-se assim que os objetos emblemáticos enquanto objetos semióforos se determinam a partir de elementos cuja relação entre indivíduo e objeto se constrói a partir de um espectro aurático em que se consideram a história do objeto, o seu valor e o discurso ao qual se encontra construído (Bergeron, Goulet, \& Rodrigues, 2016).

Segundo Baudrillard (2008), a funcionalidade do objeto, substituída pelos significados a ele atribuídos, se transforma segundo o contexto em que se encontra em um sistema que lhe permite responder acerca da perda da função original, mas que segundo a história e memória nele contidas remete ao passado para construção de seus significados e valores presentes. A funcionalidade passa a significar, assim, um contexto passado de consumo e de experiências cujas relações mercantilistas em que se encontravam passam a ser transferidas para uma cultura do poder, museal ou patrimonial, retratada pelo valor simbólico e pelos diferentes significados a ele atribuídos. 
Com isso, o objeto que anteriormente se potencializava a partir de sua funcionalidade e usabilidade, de sua relação com o mundo real e, consequentemente com as necessidades do homem, passa a objeto de significados e de consumo (de valores, de signos) simbólico (de desejos, de significações e de identidade).

Esta construção do significado determina consigo uma materialização de ideias cuja representação se constitui novos elementos de referência segundo os quais se determina um 'novo' discurso museal (ou patrimonial) em que se tem o reconhecimento de sua singularidade ou excepcionalidade, seja para o indivíduo ou para os grupos, comunidades ou sociedades em que se encontra inserido. Esta mudança de paradigma em que se tem a transposição de relevância do objeto de sua relação de funcionalidade/utilidade para uma relação de significância/significado determina aos objetos semióforos, e consequentemente, aos objetos emblemáticos uma dessocialização do objeto (perda de sentido), em um momento passado, e sua posterior ressocialização (refuncionalização museal/patrimonial) como signo e representação de significados passados.

Devallon (2010), reforça a ideia de uma relação construída entre espectador e objeto a partir das exposições ou das formas de apresentação dos objetos a terceiros a partir da qual ele propõe um processo de reciprocidade. Nele ocorre uma contextualização do objeto a qual ocorre segundo uma recriação realista do contexto de origem, denominada diorama, em que se tem uma imersão simbólica de sentidos seja das características visíveis ou invisíveis dessa relação objeto-indivíduo.

Essa construção determina, assim, ao espectador, uma possibilidade de experienciação ou experimentação de sentidos que transmuta a questão racional, da construção de signos e significados a partir da funcionalidade e usabilidade percebidas, mas que se funda na identidade transcendental que perpassa por questões de sensibilidade e corporeidade em que o espectador se coloca para além do espaço e tempo apresentados pelo objeto e se transmuta a outro campo espacial-temporal de experimentação. Com isso, a própria representação do objeto e sua carga de signos e significados lhe determina o caráter emblemático, de simbolismo, simulações e simulacros os quais se aproximam dos conceitos de Baudrillard (2008) com relação à espetacularização do objeto e sua capacidade de construção de uma realidade etérea e representativa de uma realidade não-existente.

Complementa-se a essas ideias, as interpretações de Meneses (1994) para os objetos emblemáticos, os quais se encontram carregados de significados - quer sejam relíquias, semióforo ou objetos históricos - carregados de compromissos com o presente, pois nele se produzem e se reproduzem como categoria de objeto e a partir dessa capacidade mimética se conformam às necessidades do presente as quais eles respondem e correspondem.

Assim, se contrapõem à resistência de significados ou signos que ocorre a partir de uma ausência de identidade e identificação a qual desemboca no que se pode determinar como 'fantasma' das coisas cuja proliferação desenfreada determinaria uma ruptura com relação à memória e a história. A força adquirida pelos objetos e seus significados compreende uma contínua construção de elementos de comunicação que criam identidades e relações próprias entre elementos do passado que se fazem presente e se perpetuam no futuro.

O objeto emblemático transmuta-se assim entre o objeto metonímico de Meneses (1994) em que se tem a perda do valor documental por uma transformação em ícone cultural, como elemento de identidade que apreende situações especificas as quais estão carregadas de significados que se traduzem em uma simplificação ingênua de um sistema complexo de variáveis determinantes às culturas sociais ou mesmo a sua exclusão. Complementa-se assim o objeto a sua característica metafórica que se revela a partir de uma relação de substituição de sentido em que se observam sentidos, ideias e conceitos os quais se formam a partir da interpretação externa ao próprio objeto e segundo um caráter de identificação, ou mesmo de identidade entre a sua representação e a relação com o outro.

Nesse sentido, Bergeron (2015), entende que os objetos emblemáticos enquanto os objetos-chave "são os melhores exemplos que permitem a compreensão do museu como um teatro de objetos e permite identificar o papel do imaginário nos museus" (p. 48). Essas possibilidades inerentes aos objetos museais, de se revestirem de significados e a partir deles construir uma aura imagética 
que somente aqueles que a constroem são capazes de percebê-la, entendê-la e compreendê-la em sua essência.

\section{0 patrimônio ferroviário e as rotundas}

As grandes estruturas e estações ferroviárias, desde o século XVIII significam não somente um conjunto de edifícios relacionados à prestação de serviços à sociedade, que estão considerados meio de transporte e logística. Para muitas pessoas, os diversos edifícios e espaços ferroviários têm diferentes signos e significados que se supõe também apresentem uma identidade com pessoas, grupos e sociedade (cidades) para além do símbolo de desenvolvimento e progresso (até meados do século XX) e atraso, infelizmente para muitos, no Brasil, após os anos 50 e 60.

0 complexo ferroviário se desenvolve não somente às atividades diretamente relacionadas à logística e transporte, mas também às estruturas sociais, em geral a ele circunscritas. Muitas atividades indiretamente se relacionam aos seus elementos, a partir dos quais se define uma paisagem que apresenta um grande elemento central, a Estação, que por suas características próprias permitiu uma identificação social. Desde a chegada e partida de pessoas aos processos de carga e descarga de produtos e serviços, as estacoes ferroviárias e seus complexos estão, de diversas maneiras, relacionados à memória e à história de indivíduos e sociedades. Assim, o conceito de memória compreende muitas variáveis que se entrecruzam e se inter-relacionam a partir de uma condição interdisciplinar.

A memória dos indivíduos que se constrói a partir da relação com elementos do complexo ferroviário ocorre de maneira efetiva em muitas das cidades e núcleos rurais e urbanos brasileiros em que esteve presente esse tipo de modal de transporte. Apesar de fazer parte da realidade atual, as memórias e a identidade ferroviárias se perpetuam de diversas maneiras. Em sua quase totalidade, em um passado não tanto recente, o complexo ferroviário brasileiro, principalmente de passageiros, sofreu um grande impacto negativo a partir dos anos 60 que se intensificou nos anos 80, do século XX.

Entretanto, quando se relaciona os estudos de memória à história se pode reviver ou fazer presente uma memória social e coletiva, representada, por exemplo, por uma identidade ferroviária. Dentre as diversas análises possíveis, se constrói a memória a partir de quadros de representação e suas relações com a memória coletiva em que se verifica a amplitude das interações sociais estabelecidas. Muitas análises realizadas desenvolvem questões que relacionam a memória, sua construção e relações às identidades pessoal e coletiva que se apropriam de elementos comuns e de identificação. (Santos, 1998).

Dessa maneira, a memória pessoal relacionada à memória ferroviária, como um elemento específico, determina, segundo Halbwachs $(1990,2004)$ a memória coletiva que considera a construção no presente de fatos passados os quais trazem significados para um determinado e específico grupo. Estas recordações têm significados próprios e garantem importantes graus de identificação e identidade. Geralmente se estabelecem a partir de mudanças e transformaç̧ões que se constituíram como elementos-chave em um determinado tempo e espaço na vida das pessoas que pertencem a eles.

Pode-se assim relacionar o conceito dessa memória ferroviária ao conceito de patrimônio cultural cujo conceito construído pelo IPHAN (Instituto do Patrimônio Histórico e Artístico Nacional) privilegia, de certa maneira, a preservação que promove "a interação entre ambiente, natureza $e$ história, gerando um sentimento de identidade e continuidade, contribuindo assim para promover o respeito à diversidade cultural e à criatividade humana".

As diferentes maneiras de articulação existentes entre a cultura e a memória, a história e a sociedade, reescrevem um passado e presente, muitas vezes recente, mas esquecido. Além disso, definem novas maneiras de se enxergar as fronteiras e articulações que identificam uma linguagem nacional própria e uma identidade e memória sociais que muitas vezes são significantes e trazem significado a questões que inquietam estudiosos e apaixonados pela memória cultural. (Ferreira \& Orrico, 2002) 
Segundo Choay (2001), tais características particulares garantem maior abrangência ao patrimônio cultural quando relacionado à natureza e escala diferenciadas que determinam uma maneira única ao se tratar sua definição e sua identificação e identidade. A mera classificação de edifícios ou de aspectos arquitetônicos não permite abarcar as possibilidades de identificação do patrimônio, uma vez que se pode considerar todo um território de influência que possui formas de expressão.

Nesse sentido e se considerando os componentes construídos e/ou modificados pelo homem, deve-se dar relevância à vida social, às construções e ao desenvolvimento urbano das cidades e da sociedade que não podem ser vistos de maneira independente e desconectados. As diferentes relações que se estabelece entre sociedade e organizações (ou pode-se dizer empresas) determinam perspectivas particulares para a construção de conceitos de patrimônio e cultura que extrapolam os aspectos comumente abordados.

Sob essa perspectiva, a memória e a cultura social se compõem de um imaginário que se relaciona à percepção dos grupos sociais e dos indivíduos que se identificam segundo determinadas perspectivas envolvendo, inclusive, o campo do trabalho. A construção do eu (indivíduo) e do social (grupos, comunidade) decorre, assim, de experiências vividas que incluem aquelas ocorridas no âmbito do trabalho e das organizações e por eles determinadas.

Apesar da ampliação das percepções do conceito de patrimônio, deve-se considerar que atualmente, segundo Araújo (2009), a análise e interpretação dos conjuntos considerados patrimônios culturais, no Brasil, encontra-se determinada por parâmetros tradicionais e somente permitirá mudanças e ampliação se houver uma atuação compartilhada entre os diversos indivíduos e grupos envolvidos, além de uma capacidade de construção de identidade e identificação das paisagens culturais pelas populações de seu entorno. Complementarmente, para um entendimento global da paisagem cultural, torna-se necessário compreender o conceito de paisagem cultural conjuntamente àquele relacionado à construção de contribuições destinadas ao entendimento dos lugares e maior capacidade de compreensão dos espaços, bem como dos aspectos socioculturais a eles relacionados.

Dessa maneira, pode-se perceber a utilização de uma abordagem interdisciplinar que torna possível um amplo entendimento dos conceitos relacionados ao patrimônio cultural e à paisagem cultural. Uma percepção integrada de diferentes áreas do conhecimento possibilita o desenvolvimento de novos campos do saber e envolve uma dinâmica de (re)construção ou (re)definição das formas de atuação e percepção dos lugares, por parte de grupos e/ou indivíduos que determina novas formas de pensar.

\section{A rotunda ferroviária - um objeto emblemático da paisagem ferroviária}

As rotundas ferroviárias (em inglês, roundhouses; em espanhol, casas redondas) se destacam por sua importância quanto à manutenção das locomotivas e máquinas de tração ferroviárias. A partir de sua identificação nos complexos ferroviários percebe-se certa imponência arquitetônica, por se constituírem como um dos grandes edifícios e uma das principais áreas dos complexos ferroviários. Esses elementos da estrutura ferroviária despertam interesse, desde sua centralidade nos espaços e paisagens ferroviários como a admiração das pessoas por seu tamanho, forma e complexidade.

No Brasil, segundo Morais (2000), existiram ao todo cerca de 24 rotundas ferroviárias, sendo que, atualmente elas se restringem a um número total de 15 exemplares. Tal fato ocorre por estarem situadas, de maneira geral, em áreas conturbadas pelas cidades e por se situarem em áreas de grande interesse especulativo do capital. Geralmente as estruturas tinham como principal característica arquitetônica o aspecto poligonal que compreendia uma circunferência completa ou um arco de circunferência e se diferenciava de outros tipos de depósitos de máquinas os quais apresentavam uma arquitetura poligonal retangular que se compunha de edifícios e de um elemento denominado girador ou viradouro o qual posicionava as máquinas para sua entrada e saída.

As rotundas, segunda Kühl (1998), estão caracterizadas por sua forma hexagonal ou cilíndrica, mas também em muitos casos em meia circunferência. Os edifícios destinados às máquinas locomotoras tinham capacidade de guarda entre quatro e oito máquinas, em geral, mas os maiores depósitos podiam receber até vinte locomotivas. Sua principal característica centra-se no girador ao centro de sua estrutura o que possibilita o posicionamento das máquinas nas garagens vazias. As rotundas 
que não tinham sua parte central coberta eram denominadas "anelares", diferentemente daquelas cobertas que eram chamadas simplesmente de "rotundas". As dimensões foram gradualmente evoluindo de um diâmetro de 37 metros e capacidade para 12 máquinas na década de 1830-40 para 110 metros de diâmetro e capacidade para 70 máquinas na década de 1900-1910.

Observa-se de maneira interessante que no período das Grande Guerras a estrutura das rotundas não foi destruída, assim como outros exemplares de grandes edifícios a pesar de poder se tornar um alvo em potencial devido à sua centralidade para o transporte ferroviário. Uma vez destruído o girador que posicionava e permitia a retirada das locomotoras, tornava-se impraticável a utilização do transporte ferroviário.

Ao diferenciar-se das outras estruturas ferroviárias, principalmente por seu formato, as rotundas podiam ser consideradas elementos especiais do conjunto pois determinavam novos espaços considerados sociais ou de trabalho, ou ainda privativos. Elas foram dedicadas a funcionar como abrigos ou refúgios de funcionários e passageiros, pois suas estruturas semicobertas ofereciam proteção aos passageiros que não estivessem nas plataformas ou mesmo alternativa às plataformas descobertas, às cabines ou guaritas (dos guardas ferroviários), às pontes de pedestres ou passagens subterrâneas.

Destacam-se ainda como referência espacial em relação a outros elementos de menor tamanho, como as caixas d'água, os depósitos; os banheiros e bebedouros. Conclui, a partir da multiplicidade de estruturas ferroviárias existente que compõem o complexo ferroviário, são as diversas possibilidades de se recuperar e valorizar elementos do patrimônio ferroviário cuja importância não se encontra somente pela preservação do patrimônio e da memória, mas também pela manutenção e desenvolvimento da memória e história social.

\section{A rotunda ferroviária de ribeirão vermelho}

\subsection{Histórico Ferroviário}

A história ferroviária do Brasil começou nos anos 1852 quando o Barão de Mauá construiu a primeira via férrea entre as cidades do Rio de Janeiro e Petrópolis, a primeira capital do império brasileiro e a segunda cidade escolhida pela família real brasileira para viver. Na então província de Minas Gerais, as origens da história das ferrovias estão vinculadas à Estrada de Ferro Oeste de Minas - EFOM -, de 1881 e da Rede de Viação Sul Mineira - RVSM, de 1922, que duas foram reunidas na RMV - Rede Mineira de Viação nos anos de 1931.

Inicialmente, nos anos 1880, a ligação entre a cidade de Sítios (atual Antônio Carlos) e a navegação fluvial do Rio Grande, em Ribeirão Vermelho. Depois houve sua ampliação com as linhas até as cidades de Oliveira (1888) e Paraopeba (1894). A amplitude de influência determinou uma maior capacidade para a navegação fluvial do Rio São Francisco até a cidade de Pirapora. Assim, a partir da cidade de Ribeirão Vermelho se tinha um total de $208 \mathrm{~km}$ de extensão de linhas férreas que acompanhavam o rio e faziam a integração entre as duas bacias hidrográficas.

O Governo Federal, já republicano, em 1903, adquiriu as linhas de Cedro a Rio Claro que foram incorporadas, assim à EFCB (Estrada de Ferro Central do Brasil) e também se concluiu os trechos incompletos de Belo Horizonte a Divinópolis. Tem-se, também que em 1890, a EFOM recebeu a concessão federal para uma linha de Barra Mansa (RJ) a Catalão (GO), com largura de bitola ferroviária de 1,00 m e outra concessão estadual complementar até Angra dos Reis (RJ), cujo trecho denominou-se "corredor de exportação" desde Goiás (Martyre, 1975; Gonçalves, 1996).

Meio século após, nos anos 1953, a RMV passou às mãos do governo com a criação do DNEF Departamento Nacional de Estradas de Ferro e da RFFSA - Rede Ferroviária Federal S.A. Com isso, em 1957, os trechos passam a integrar a nova rede de ferrovias, sendo em 1965 denominada de Viação Férrea Centro-Oeste - VFCO. A partir dos anos 1975 todas as linhas ferroviárias da RFFSA passaram a ser denominadas por sua sigla até 1996, quando, finalmente, houve o processo de privatização das redes ferroviárias brasileiras. Os trechos determinados anteriormente pela VFCO passam a denominar-se Ferrovia Centro Atlântica, ou FCA. 
A relação estabelecida com a cidade de Ribeirão Vermelho foi determinada pelo entroncamento das linhas em seu território o que levou a certa importância na história social e econômica do Estado e, consequentemente do complexo ferroviário. Essa centralidade levou a implantação de um complexo de apoio ferroviário que permitiu à cidade um desenvolvimento social e urbano leva a pensar em certa centralidade da região no que tange ao surgimento à época de oportunidades de trabalho e de desenvolvimento econômico que poderiam ser relevantes para um incremento do turismo e da consciência histórica e patrimonial. Com isso, a importância de reconhecimento histórico e da memória do lugar determina à cidade e seu complexo ferroviário certa preocupação, principalmente em relação à rotunda ferroviária que se encontra em situação de deterioração e perda de elementos construtivos e arquitetônicos.

\subsection{Descrição arquitetônica e construtiva}

A partir da descrição típica das Estações Ferroviárias no Brasil tem-se uma certa identidade e identificação com os elementos que compõem o Complexo Ferroviário da cidade de Ribeirão Vermelho. Como se trata de uma estação de entroncamento que buscava a ligação entre linhas de redes ferroviárias diferentes se buscou por suas características uma comparação com outra de igual função, a estação ferroviária da cidade de São João D'El Rey que também se constituiu o centro de confluência de linhas.

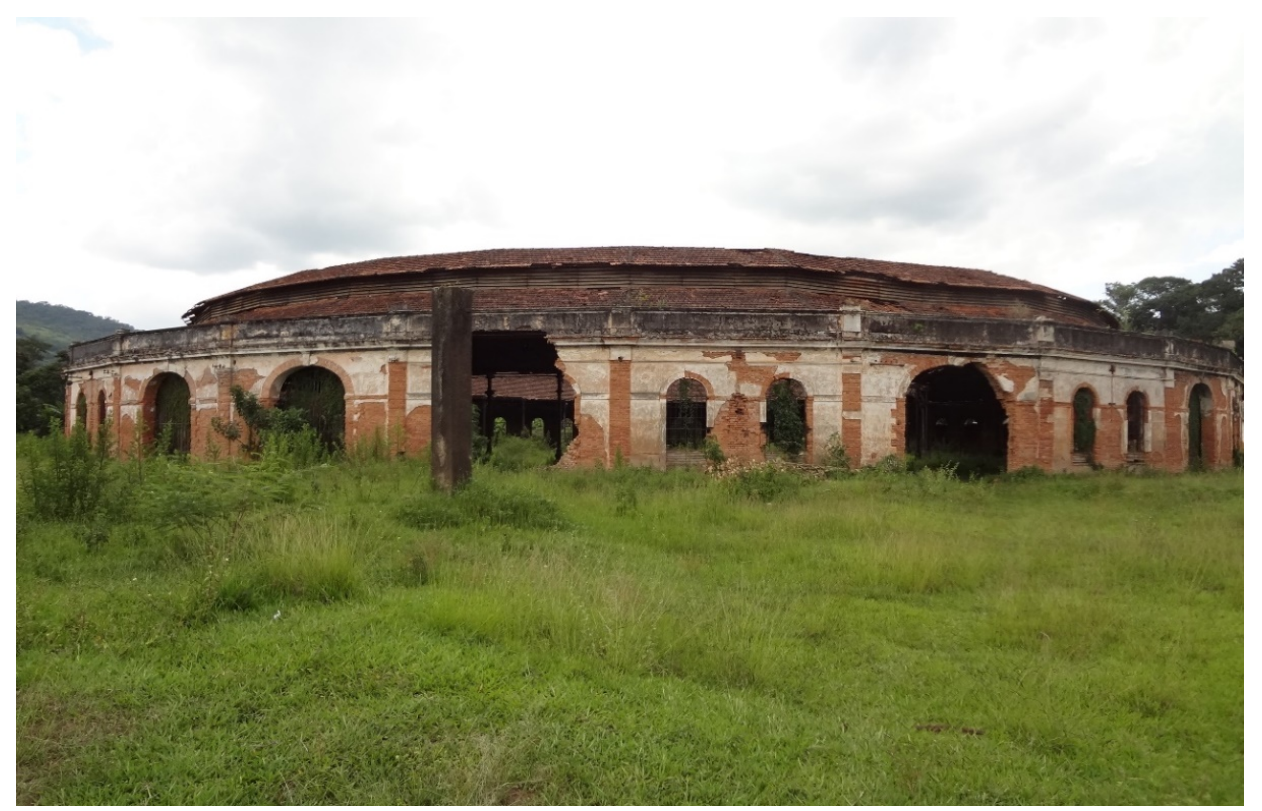

Figura 1. A Rotunda Ferroviária de Ribeirão Vermelho, em Ribeirão Vermelho [MG] Brasil. Fonte: Ronaldo André Rodrigues, 2015.

O conjunto ferroviário inclui as oficinas, escritórios, armazéns e demais edifícios de um complexo ferroviário. Assim como a estrutura do Complexo Ferroviário de São João D'EI Rey que possui um pátio principal e edifícios de arquitetura significativa, construídos a partir das tradições europeias do final do século XIX e início do XX. A rotunda do complexo ferroviário foi construída em 1895, pela Cia. Estrada de ferro Oeste de Minas, A estrutura foi feita com material importado da Escócia, as cerâmicas (tijolos) são francesas e os equipamentos, máquinas e projeto ingleses (Figuras 2a e 2b).

Segundo as semelhanças existentes entre a rotunda do Complexo de São João D'El Rey e a do Complexo de Ribeirão Vermelho, tem-se que ambas se destacam segundo o ambiente em que se encontram, seja por suas características ou pelas dimensões que possuem. Infelizmente, a maior parte dos documentos encontrados não fazem referência à rotunda e consequentemente ao Complexo de Ribeirão Vermelho. Entretanto, uma diferença que se pode perceber entre as duas está relacionada à primeira que possui um pátio ferroviário no centro do complexo, enquanto a segunda encontra-se localizada entre a estação e os armazéns e oficinas. 


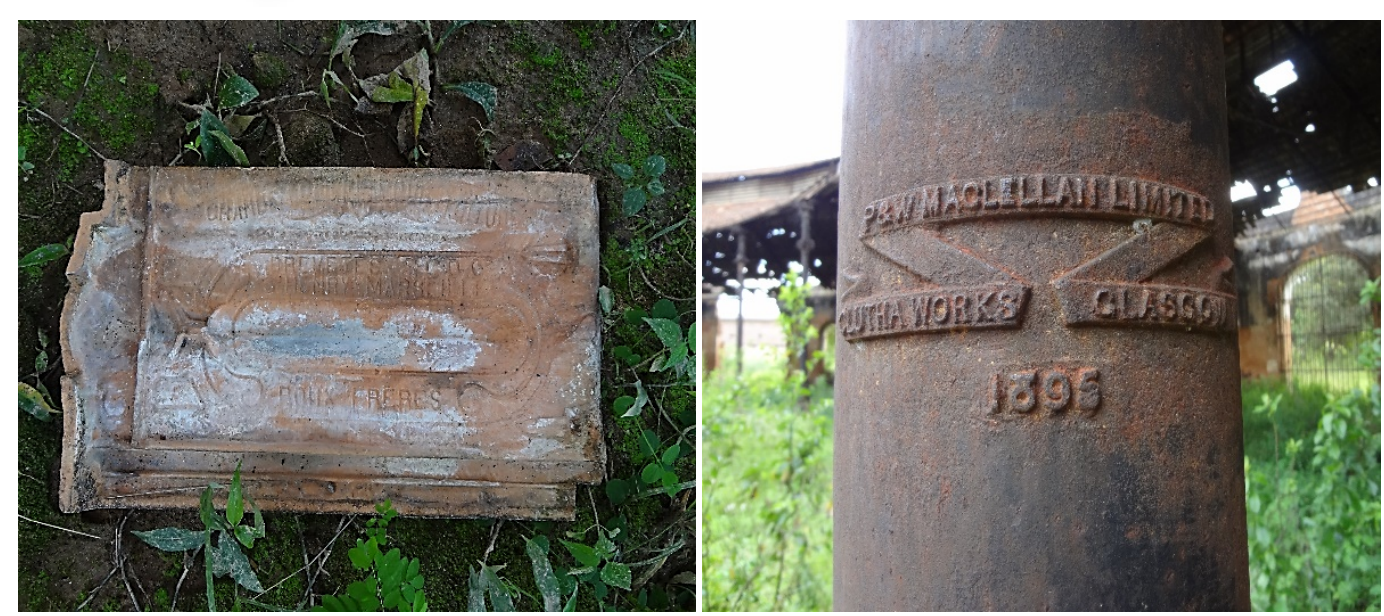

Figura 2. (a) Telhas francesas e (b) estrutura metálica escocesa. Fonte: Ronaldo André Rodrigues, 2013.

A estrutura original da rotunda de Ribeirão Vermelho apresenta semelhanças comparáveis a de um anfiteatro greco-romano com uma estrutura arquitetônica do tipo poligonal. Por possuir oficinas de manutenção e conservação das máquinas motrizes e, também, por ser uma estação-tronco de confluência de linhas, possui um girador central para a mobilização e posicionamento das maquinarias. A partir da observação de sua estrutura construtiva e sua comparação com a existente na cidade de São João D'El Rey cuja estrutura está embasada em construção civil de tijolos que utilizou pedras como base de sustentação e, igualmente, para as paredes que também foram construídas com densa estrutura.

A cobertura da rotunda de Ribeirão está composta, como escrito anteriormente, por cerâmicas francesas, com estrutura de madeira e sustentada por colunas de ferro fundido escocês as quais encontram-se apoiadas em colunas construídas em pedra lavrada. 0 espaço interno da rotunda é continuo, para permitir a plena mobilidade das máquinas. Para tal, buscou-se adequar a disposição das colunas com a finalidade de possibilitar e facilitar a entrada e saída das máquinas. Uma percepção similar se pode observar na estrutura compreendida pela rotunda do Complexo de São João D'El Rey (Rodrigues da Silva, 2014a).

Complementarmente, como valorização não somente da rotunda, mas de todo o complexo, temse as estruturas dos armazéns e da estação ferroviária central, cujos projetos e análise estrutural permite uma generalização em relação a maioria das estruturas encontradas nas demais estações ferroviárias brasileiras do final do século XIX e início do século XX em que houve grande influência europeia. Dentre os estilos de construção das estaciones e por pertencer ao interior brasileiro, sem perspectivas de grande desenvolvimento econômicas, apesar do intuito de povoar o interior do país, a estação de Ribeirão Vermelho se apresenta com estrutura descrita como "arquitetônica simples".

Outra característica do Complexo de Ribeirão Vermelho se relaciona à própria expansão da cidade e uma certa marginalização em relação à estrutura ferroviária. Tal característica se intensifica com a perda de centralidade do desenvolvimento econômico pela estrutura ferroviária o que leva a certa inutilização da estação, com o término do uso do uso para passageiros e do encerramento das atividades de manutenção ferroviária do complexo. 0 processo de desativação da estrutura férrea e sua posterior deterioração e parcial destruição determina um mesmo fim à rotunda ferroviária e a todo complexo ferroviário.

\section{A rotunda ferroviária e seus aspectos emblemáticos}

Ao se analisar o tratamento dado pelos órgãos públicos com relação ao patrimônio ferroviário e o descaso quanto a sua destinação, utilização e reativação entende-se, parcialmente, as consequências a que estão destinadas as estruturas férreas do país, e particularmente o Complexo Ferroviário de Ribeirão Vermelho.

A própria cidade de Ribeirão Vermelho se identifica oficialmente com o Complexo Ferroviário como principal elemento de identidade e de significado para a comunidade. Na página principal 
do município tem-se na parte superior uma fotografia em que se tem a vista da paisagem ferroviária formada pelo conjunto ferroviário, em uma visão panorâmica (Figura 3) e outra de parte da estação ferroviária.

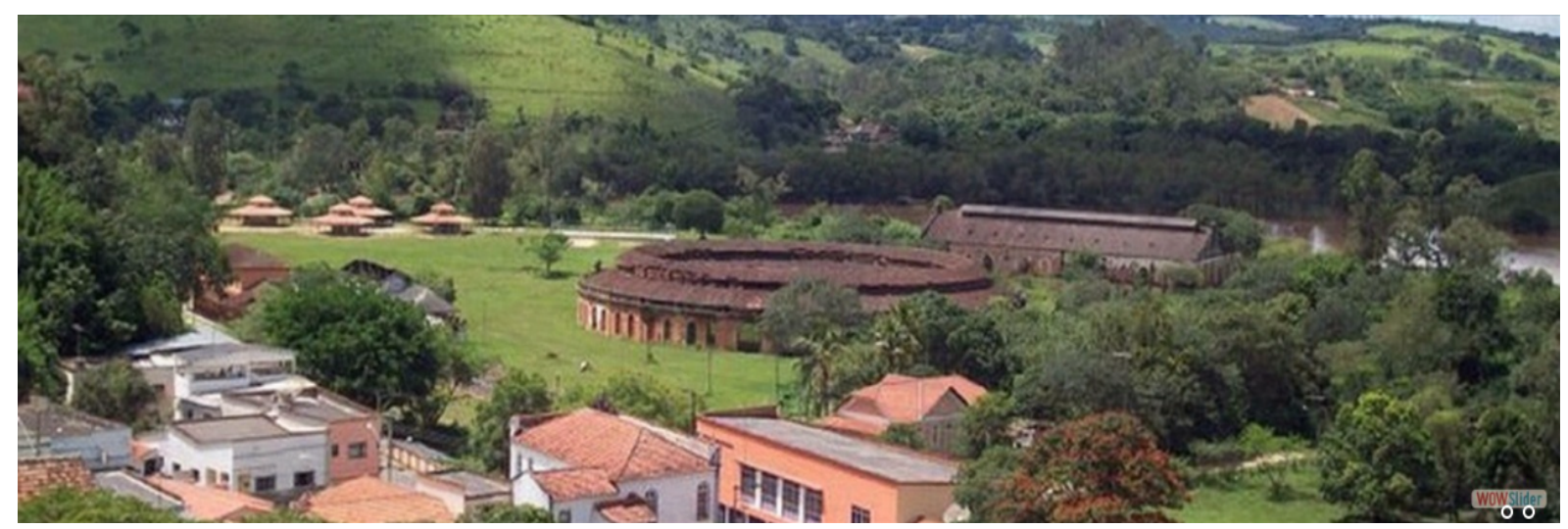

Figura 3. Vista Geral do Complexo Ferroviário de Ribeirão Vermelho.

Fonte: Página Oficial da Prefeitura Municipal de Ribeirão Vermelho - http://www.ribeiraovermelho.mg.gov.br/

Entretanto, percebe-se uma preocupação subsidiária da gestão municipal em promover o município sem uma preocupação integrada com a buscar financiamentos e possibilidades para a manutenção e preservação do conjunto cuja condição de preservação define uma possibilidade de interpretação da centralidade do Complexo em decorrência do reconhecimento em 2014, em 19 de agosto, pelo Instituto Estadual do Patrimônio Histórico e Artístico de Minas Gerais - IEPHA-MG, do "Conjunto Arquitetônico e Paisagístico Ferroviário de Ribeirão Vermelho" como patrimônio cultural do Estado de Minas Gerais (IEPHA, 2014). 0 processo se confirma com a publicação no Diário Oficial do Estado, em 12 de dezembro de 2014, da ata da reunião em que se tem oficializado o reconhecimento:

\begin{abstract}
Tombamento do Conjunto Arquitetônico e Paisagístico Ferroviário de Ribeirão Vermelho - município de Ribeirão Vermelho. A gerente de Patrimônio Material do IEPHA, Rosana Marques, apresentou o histórico do bem cultural, fotografias e os elementos arquitetônicos presentes no conjunto analisado. Além das diretrizes de tombamento, foi apresentada uma proposta inovadora que diz respeito ao plano de salvaguarda para o conjunto. Para elaboração do plano, a proposta é a formação de um comitê formado por setores interessados na preservação do conjunto visando a sustentabilidade da gestão com participação de representantes da Secretaria Municipal de Cultura, Secretaria Municipal de Educação, Conselho Municipal de Patrimônio, CONEP, IEPHA, IPHAN, Associação Comercial de Ribeirão Vermelho, Associação de Ferroviários e demais lideranças comunitárias. O plano deverá compreender programa de conservação e restauração com estudo de viabilidade de usos potenciais compatíveis à preservação e identificados a partir das dinâmicas socioeconômicas da região. [...] RECOMENDA-SE o tombamento do Conjunto Arquitetônico e Paisagístico Ferroviário de Ribeirão Vermelho pelo Conselho Estadual do Patrimônio Cultural - CONEP, bem como a elaboração do Plano de Salvaguarda desse Conjunto, conforme proposto pelo IEPHA/MG" (Item III - Processo CONEP no 003/2014, DOE-MG, Caderno 1, Diário do Executivo, p. 63).
\end{abstract}

A proposta inicial, no ano de 2014 inclui ainda um encaminhamento oficial para reconhecimento do tombamento em nível nacional, o que não se concretizou no curto prazo, não somente com o complexo ferroviário de Ribeirão vermelho, mas também com outros remanescentes do conjunto ferroviário nacional os quais sofrem com a falta de proteção, destinação e uso. Entretanto, temse aberta uma possibilidade oficial de valorização e preservação do conjunto e sua posterior sustentabilidade com o reconhecimento histórico e patrimonial que se posiciona contrariamente a inúmeros processos de abandono e esquecimento em relação à memória ferroviária local, regional e nacional (Figura 4).

A repercussão imediata do tombamento, à época, foi uma divulgação nas mídias, dentre elas o principal veículo de comunicação escrita do Estado de Minas Gerais, o jornal estado de Minas, que publicou uma matéria sobre o processo de tombamento e apresentou como símbolo do Complexo Ferroviário a sua rotunda. (Figura 5). 


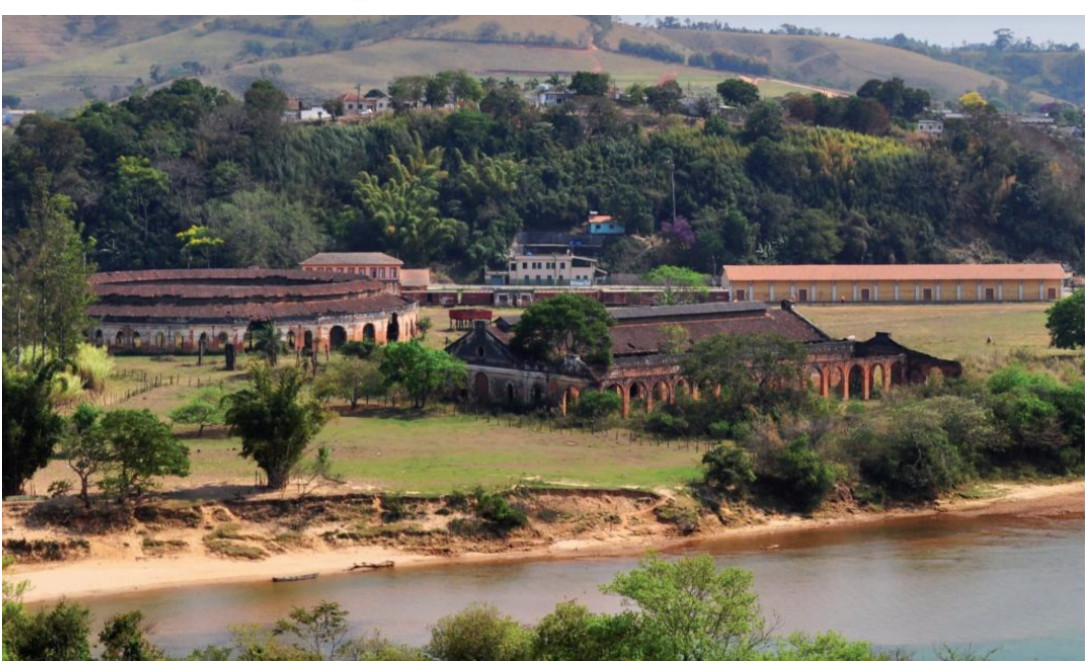

Figura 4. Complexo Ferroviário de Ribeirão Vermelho.

Fonte: IEPHA, p. 22, 2014.

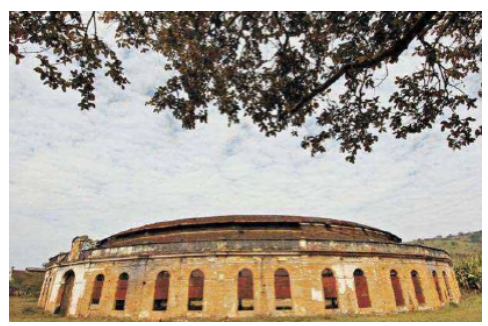

Figura 5. Rotunda do Complexo Ferroviário de Ribeirão Vermelho. Fonte: Estado de Minas, 22 nov. 2014 - www.em.com.br

Um dos possíveis embriões de reconhecimento do Complexo Ferroviário com elemento de importância para o Estado e também uma preocupação nacional encontra respaldo na Portaria №. 29/2009, da Procuradoria Geral da República em posicionamento ao Instituto do patrimônio Histórico e Artístico nacional, o IPHAN, órgão de proteção do patrimônio cultural brasileiro, o posicionamento do Ministério Público Federal em favor da necessidade de maior preocupação com a proteção do patrimônio público e social, em especial do patrimônio cultural, e especialmente os elementos do patrimônio ferroviário nacional. Em particular encontra-se citado o complexo ferroviário de Ribeirão Vermelho.

[...] a preservação e a difusão da memória ferroviária constituída pelo patrimônio artístico, cultural e histórico do setor ferroviário serão promovidas mediante ações tais como a conservação e a restauração de prédios, monumentos, logradouros, sítios e demais espaços oriundos da extinta RFFSA (art. 9o, §2으, II da mesma Lei); [...] o município de Ribeirão Vermelho detém complexo ferroviário de grande imponência, composto de edificações de provável relevo no contexto da história da implantação e do desenvolvimento da atividade ferroviária no Brasil e na articulação desta com o cotidiano das sociedades direta ou indiretamente dela dependentes; [...] várias das edificações em questão, formadoras de paisagem cênica de rara expressão, encontram-se em estágio de ruína avançada, notadamente os antigos galpões e a rotunda, esta dotada de belas linhas arquitetônicas e por muitos considerada como sendo a maior da América Latina, sujeitos a ações de vandalismo e ao paulatino desaparecimento; [...] (Portaria №.29, MPF/PGR, p. 2, 2009).

Tem-se então, aberta a possibilidade de reencaminhamento do processo às autoridades competentes a fim de que se possa desenvolver um planejamento e posteriores ações que venham a permitir, conforme o documento a valorização, preservação e conservação de "Vestígios arqueológicos ferroviários entre a preservação e o abandono" e o apensamento do "Projeto Parque Histórico Ferroviário sobre Trilhos".

Observa-se ainda o caráter de centralidade e reconhecimento da cidade de Ribeirão vermelho ao se buscar no Google Fotos os termos "Ribeirão Vermelho" e "Minas Gerais", em que se tem, dentre os itens que aparecem na primeira página dos resultados, cerca de $80 \%$ referentes ao complexo ferroviário, com particular interesse pela rotunda, com aproximadamente $25 \%$ das imagens, conforme apresentado na Figura 6.

Entretanto, percebe-se ainda, mesmo que após o reconhecimento da necessidade de preservar e conservar a memória ferroviária local e estadual, um elevado grau de abandono de todo o complexo. Desde à época de seu reconhecimento até o final de 2017, ou seja, passados três anos, tem-se uma visualidade parcial do conjunto ora tombado à época. Alguns edifícios, como as oficinas e armazéns encontram-se em total estado de ruínas, sendo que durante esse período somente a estação ferroviária e um dos galpões foi reconhecidamente restaurado, mesmo que de forma parcial sem se preservar sua originalidade, funcionalidade ou mesmo características primárias. 


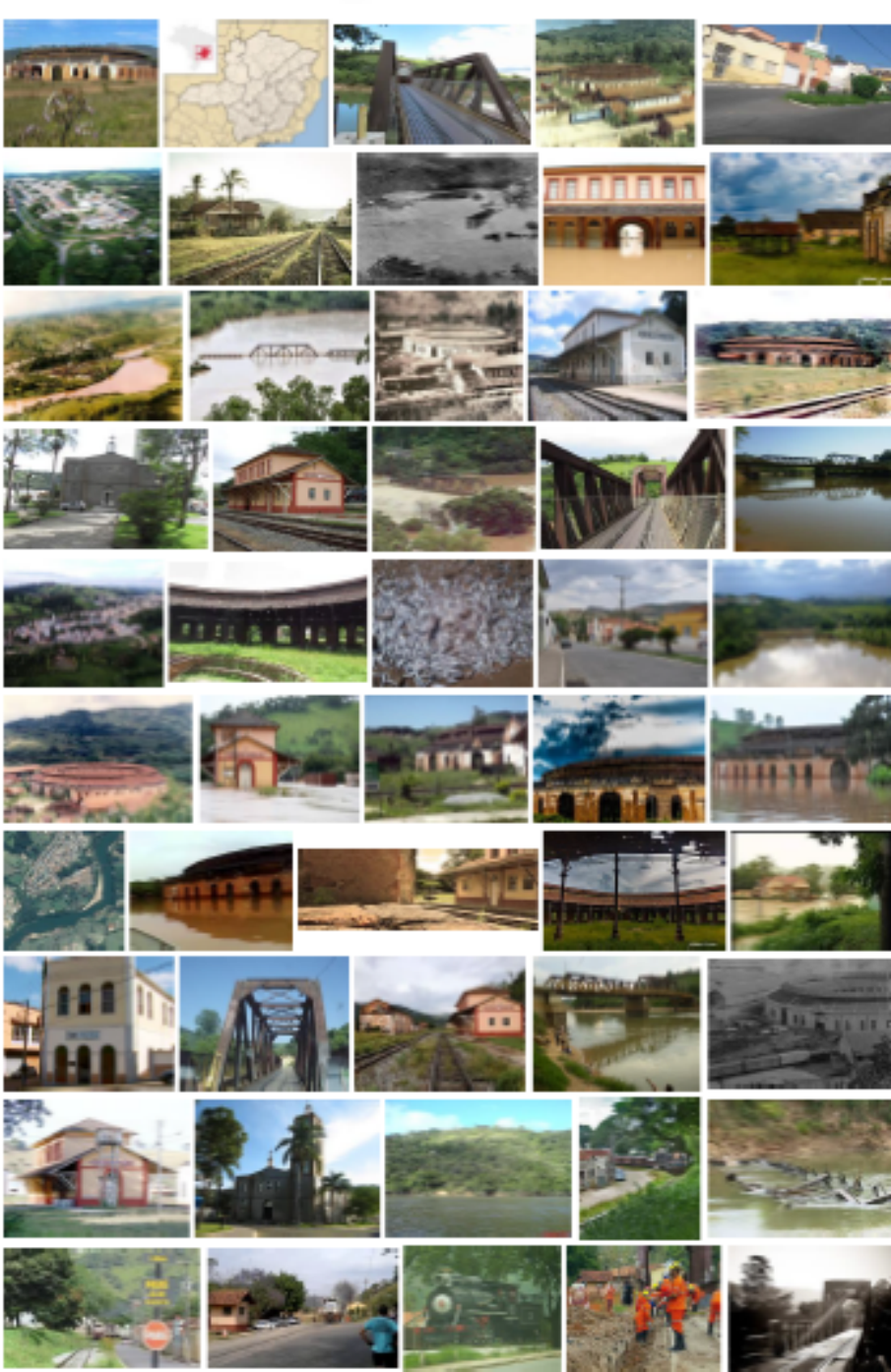

Figura 6. Ribeirão Vermelho - Pesquisa na WEB Fonte: Google Imagens, 2017.

Recentemente, ao final do mês de junho de 2017 promoveu-se, com apoio da prefeitura da cidade, a 5ạ. Etapa da Copa Sul Minas de Velocross na cidade, sendo o principal elemento do circuito a rotunda ferroviária. (Figura 7).

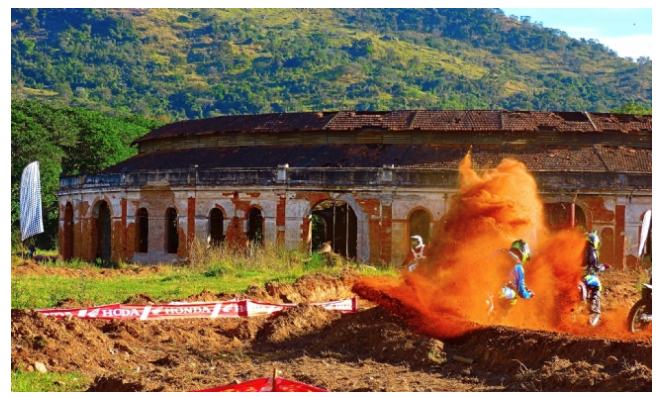

Figura 7. 5‥ Etapa do Copa Sul Minas de Velocross. Ribeirão Vemelho [MG] Brasil.

Fonte: http://www.ribeiraovermelho.mg.gov.br/ galeria.asp?id=2\&pag=92

Com o propósito de promover o turismo local e a inserção da cidade no circuito mineiro, a cidade contribui, negativamente, com a degradação e a desvalorização do elemento emblemático que a ressignifica e a identifica, em função do esporte, lazer e turismo. Percebe-se, pelos registros realizados, o estado de degradação a que está submetida não somente a rotunda, mas todo o complexo ferroviário, o qual apresenta maior dimensão quando se tem uma dimensão ampliada das consequências ambientais e paisagísticas ao se confrontar imagens do Google Earth com o antes e o depois da etapa esportiva no Complexo (Figuras 8a e 8b).

Figura 8a. Complexo Ferroviário (Ano 2003) Fonte: Google Earth, 2017.

Figura 8b. Complexo Ferroviário (Ano 2017) Fonte: Google Earth, 2017.

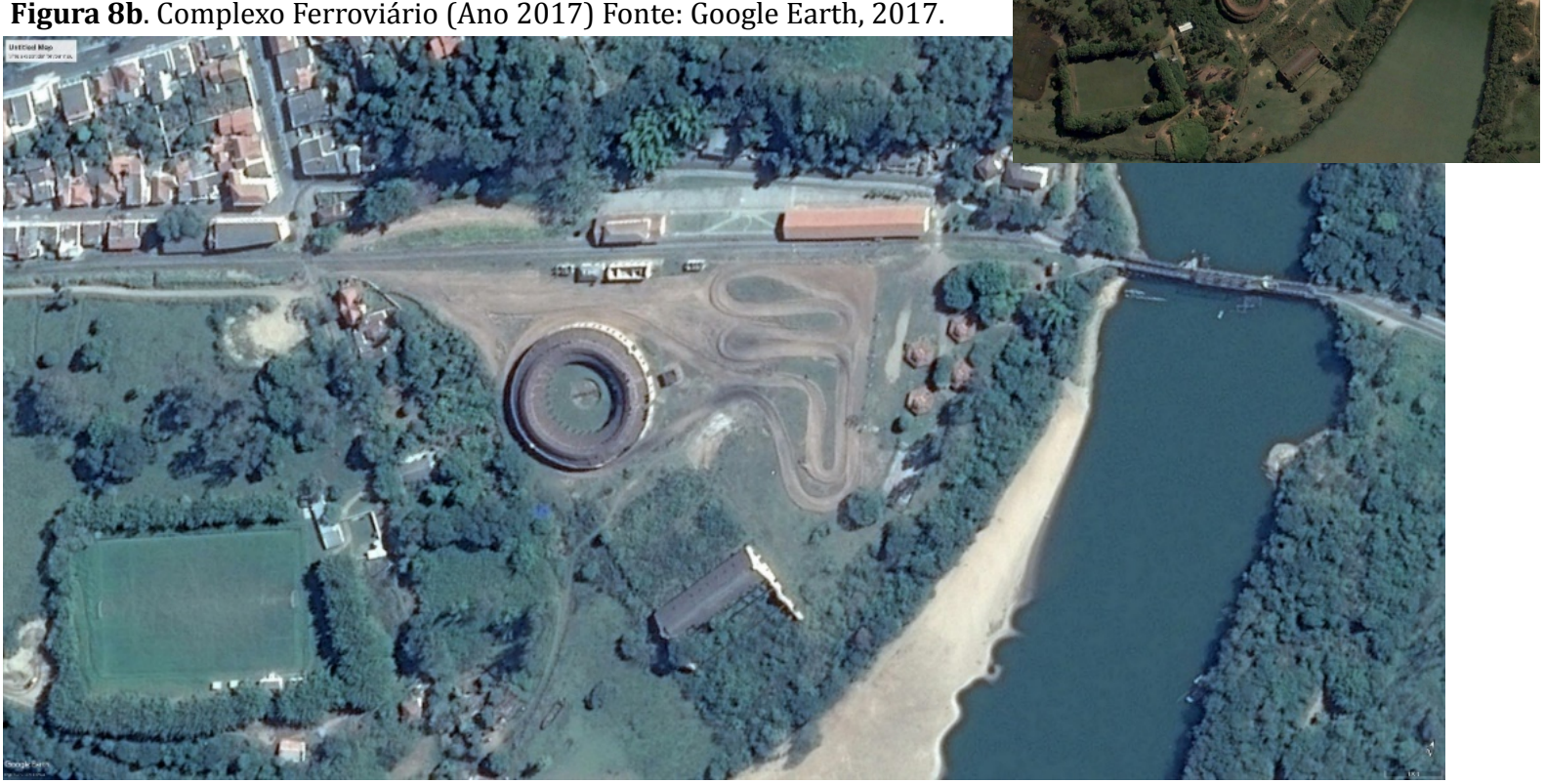

(C) Labor \& Engenho, Campinas [SP] Brasil, v.12, n.3, p.291-305, jul./set. 2018. 
Destaca-se, assim, uma situação de desconexão entre o processo de tombamento e a utilização do espaço paisagístico do Complexo Ferroviário o qual poderia ser melhor utilizado como forma de expressão artística, cultural e integração social com uma multiplicidade de situações em que se permite desenvolver diferentes possibilidades de revalorização e recontextualização. Algumas delas poderiam representar situações de reversão, reuso ou reapropriação, sem que houvesse um consequente processo de desvalorização e degradação do conjunto.

\section{Rotundas e emblemáticas reflexões}

Quando se avalia a valorização e reconhecimento do patrimônio ferroviário deve-se observar que ocorre uma multiplicidade de ações que convergem para sua incluso, mas igualmente se identifica, para um grande número de casos, a degradação, espoliação, abandono, saque e outros tipos de deterioração desse patrimônio. As diferentes interpretações que se tem do patrimônio ferroviário se constituem em realidades distintas que estão presentes nos diferentes locais.

O que se pode compreender por patrimônio ferroviária se confunde, equivocadamente, muitas vezes, à arquitetura ferroviária. Mas essa representatividade pode ser considerada complexa e corresponde desde elementos relacionados à vida ferroviária às paisagens decorrentes do complexo ferroviário, considerando-se ainda vilas ferroviárias e mesmo cidades ferroviárias que permitem múltiplas interpretações.

Quando se trata de avaliar as realidades dos elementos arquitetônicos percebem-se distintas situações, e no caso particular, as diferentes realidades que caracterizam as rotundas brasileiras que se destinam a diferentes usos e desusos na atualidade. Elas que tinham uma função específica e uma estrutura diferenciada apresentam diferentes realidades desde aquelas que contêm elementos originários de suas funções e que as mantêm àquelas que foram transformadas em Centros Culturais, órgãos públicos e outras funcionalidades. Mas também aquelas que foram totalmente destruídas ou se encontram arruinadas.

A partir de informações obtidas na bibliografia existente, a maior parte delas em sites de organizações não-governamentais e particulares, tais como a Associação Brasileira de Preservação Ferroviária $(\mathrm{ABPF})^{1}$ e o site Estações Ferroviárias. Tal processo resultou na Tabela 1, que procura esquematizar a realidade contemporânea das rotundas, segundo Rodrigues da Silva (2014b, 2015).

Tabela 1. As Rotundas Brasileiras - Localização e Situação (por região/estado).

Fonte: Adaptado/atualizado das páginas WEB: Associação Brasileira de Preservação Ferroviária (ABPF) - e do site Estações Ferroviárias. Legenda: (A ) = abandonada; ( D ) = demolida; ( E ) = existente; S/I = sem informações .

\begin{tabular}{|c|c|c|c|}
\hline Região & Estado & Cidade/Estado & Situação (*) \\
\hline \multirow[t]{2}{*}{ Norte } & Pará & Marituba & (D) \\
\hline & Rondônia & Porto Velho (Madeira-Mamoré) & (E) \\
\hline \multirow{6}{*}{ Nordeste } & Pernambuco & Edgar Werneck & (D) \\
\hline & Ceará & $\begin{array}{l}\text { Fortaleza } \\
\text { Álvaro Wayne }\end{array}$ & $\begin{array}{l}\text { (D) } \\
\text { (D) }\end{array}$ \\
\hline & Bahia & $\begin{array}{l}\text { Salvador } \\
\text { Alagoinhas }\end{array}$ & $\begin{array}{l}\text { (A) } \\
\text { (A) }\end{array}$ \\
\hline & Maranhão & $\begin{array}{l}\text { São Luís } \\
\text { Rosário }\end{array}$ & $\begin{array}{l}\mathrm{N} / \mathrm{I} \\
\mathrm{N} / \mathrm{I}\end{array}$ \\
\hline & Rio Grande do Norte & $\begin{array}{l}\text { Natal - E.F. Sampaio Corrêa } \\
\text { Natal - E.F. Natal a Nova Cruz }\end{array}$ & $\begin{array}{l}\text { (A) } \\
\text { (D) }\end{array}$ \\
\hline & Sergipe & Aracaju & (A) \\
\hline
\end{tabular}

${ }^{1}$ Site da ABPF : www.abpf.org.br / Site Estações Ferroviárias : www.estacoesferroviarias.com.br 


\begin{tabular}{|c|c|c|c|}
\hline \multirow{20}{*}{ Sudeste } & \multirow{11}{*}{ São Paulo } & Campinas (Mogiana) & (A) \\
\hline & & Campinas (Paulista) & ( D ) \\
\hline & & Bauru & (E) \\
\hline & & Ribeirão Preto & ( D ) \\
\hline & & Rio Claro & ( D ) \\
\hline & & Araraquara & $(\mathrm{E})$ \\
\hline & & Lins & (A) \\
\hline & & Casa Branca & (D) \\
\hline & & São José do Rio Preto & ( D ) \\
\hline & & Catanduva & ( D ) \\
\hline & & Cruzeiro & ( E ) \\
\hline & \multirow{5}{*}{ Minas Gerais } & Além Paraíba (Porto Novo) & (A) \\
\hline & & Ribeirão Vermelho & (A) \\
\hline & & São João Del Rey & ( E) \\
\hline & & Sete Lagoas & ( D ) \\
\hline & & Uberaba & ( D ) \\
\hline & \multirow{4}{*}{ Rio de Janeiro } & São Diogo & ( D ) \\
\hline & & Caju & ( D ) \\
\hline & & Barra do Piraí & (E) \\
\hline & & Três Rios & ( E ) \\
\hline \multirow{2}{*}{ Sul } & Rio Grande do Sul & Cruz Alta & (A) \\
\hline & Paraná & Curitiba & ( D ) \\
\hline \multirow{3}{*}{ Centro-Oeste } & \multirow{3}{*}{ Mato Grosso do Sul } & Campo Grande & $(\mathrm{E})$ \\
\hline & & Ponta Porã & $\mathrm{N} / \mathrm{I}$ \\
\hline & & Três Lagoas & $\mathrm{N} / \mathrm{I}$ \\
\hline
\end{tabular}

Segundo Tartarini (2001), ao se buscar compreender o patrimônio ferroviário deve-se avaliar de maneira interdisciplinar as suas características e funções que se constituem em elementos de identificação e identidade, pessoal e coletiva. Estas diferentes realidades podem levar a diferentes memórias e a uma história social que permite melhor descrever a realidade social em que se encontra inserido. Quando se trata de avaliar as realidades de um elemento ou de um complexo ferroviário, deve-se buscar respeitar suas características, distinções e perceber que os elementos têm usos e funções que podem não mais corresponder a uma realidade funcional, mas que, muitas vezes, se encontram relacionadas à memória e história locais.

As diferentes realidades das rotundas brasileiras e consequentemente dos complexos ferroviários levam a reflexões que tratam desde a compreensão do papel histórico e da sua pertinência à memória das populações locais até as políticas sociais e culturais de valorização desse tipo de patrimônio. Comumente não se tem valorado de maneira significativa os exemplos de patrimônio ferroviário e industrial no Brasil. Tal realidade leva a um resultado de não-preocupação, ou mesmo descaso, em relação a exemplares os mais diversos, e especificamente as rotundas em que ocorrem destruição e perda de função, além de processos de decadência das estruturas ferroviárias, em geral, desde meados do século XX, quando houve transferência do modal ferroviário ao rodoviário e posteriormente a extinção da RFFSA que determinaram a substituição por outros alternativas infraestrutura urbana ou de transportes. Pode-se distinguir diferentes realidades às rotundas, mas se deve destacar a sua importância para a memória e história de alguns centros urbanos e rurais da sociedade brasileira e, principalmente, da história ferroviária. 
O que se percebe, entretanto, é a formação de uma ideia positiva, desde órgãos públicos a privados, instituições e indivíduos que determinam uma crescente inserção de museus dedicados a esse patrimônio. Ao se considerar o potencial turístico do setor, tem-se uma realidade que representa, tão somente, cerca de $5 \%$ de todo o transporte ferroviário em 22 percursos (ANTP, 1999). No que se refere às rotundas, se destaca a existência de outros exemplares, além do especificado no trabalho, que fazem parte, igualmente, da memória e da história das cidades em que se encontram. Elas fazem parte, inseridas no complexo ferroviário, de um período passado de progresso e desenvolvimento que transformou a paisagem brasileira e permitiu o desenvolvimento socioeconômico.

Deve-se destacar que os exemplos brasileiros fazem parte de um período em que ocorreu o progresso e o desenvolvimento socioeconômico brasileiro. A estrutura ferroviária transformou a paisagem do Brasil e permitiu o alavancar da sociedade na segunda metade do século XIX e primeira do século XX. Assim, se pretende contrastar e contrapor alguns exemplos relacionados à conservação e preservação industriais, além das relações entre as paisagens industriais e culturais e a memória e história brasileiras.

Buscou-se, finalmente, apresentar as estruturas ferroviárias das rotundas como exemplares emblemáticos e remanescentes de uma história e memória sociais que, em geral, se perdem no Brasil. Em contraste a tal ponto, encontram-se igualmente exemplares cuja preocupação de valorização e preservação determina um futuro de reutilização que se apresente inserido a adequados processo e projetos de continuidade de uma memória, de refuncionalização que preserve ou rememore suas funções e que transforme a realidade de abandono em inserção ao conceito mais amplo de patrimônio cultural e paisagem cultural brasileiros.

\section{Referências}

Associação Brasileira De Preservação Ferroviária (ABPF). Site institucional. Recuperado de: $<w w w . a b p f . o r g . b r>$

Baudrillard, J.(2008) O sistema dos objetos. São Paulo: Perspectiva.

Bergeron, Y. (2015) Museus e identidades culturais (Norte e Sul da América: perspectivas de pesquisa). Anais. III Seminário Internacional Ciência e Museologia: Universo Imaginário/ Tecnologia: Informação, Documentação, Patrimônio. Belo Horizonte, p. 42-48. Recuperado de: <https://drive.google.com/file/d/ 0B1dL4PuL60ChTW1NdWJWWjJxTXc/view>.

Charpentier, N. \& Hétu, V. (s.d.) Les objets phares de la catégorie disciplinaire.

Bergeron, Y., Goulet, M. \& Rodrigues, C. (2016). Conserveries mémorielles: objets, phares des musées canadiens. Entre pratiques muséales et enjeux identitaires 19. Recuperado de: $\langle$ https://cm.revues.org/pdf/2370>.

Choay, F. (2001). A alegoria do patrimônio. São Paulo: UNESP.

Devallon, J. (2010). Comunicação e Sociedade: pensar a concepção da exposição. In: S. F. Benchetrit,, R. Z. Bezerra, \& A. M. Magalhães (orgs.). Museus e comunicação: exposições como objeto de estudo (pp. 17-34). Rio de Janeiro: Museu de História Nacional.

Estações Ferroviárias Do Brasil. Site pessoal de Ralph Mennucci Giesbrecht: Informações ferroviárias. Recuperado de: <www.estacoesferroviarias.com.br>.

Estado de Minas. Três monumentos simbólicos do interior de Minas Gerais são tombados. Recuperado de: https://www.em.com.br/app/noticia/gerais/2014/11/22/interna_gerais,592430/tres-monumentossimbolicos-do-interior-de-minas-gerais-sao-tombados.shtml.

Ferreira, L. M.A; ORRICO, E. G.D. (2002) Linguagem, identidade e memória social. Rio de Janeiro; DP\&A.

Gonçalves, T. L. (1996) Pequeno Histórico da Estrada de Ferro Oeste de Minas - EFOM. Rio de Janeiro: RFFSA.

(C) Labor \& Engenho, Campinas [SP] Brasil, v.12, n.3, p.291-305, jul./set. 2018. 
Google Images. Site institucional. Recuperado de: < https://images.google.com>.

Google Maps. Site institucional. Recuperado de: <https://www.google.com.br/maps>.

Halbwachs, M. (1990) A Memória coletiva. São Paulo: Vértica.

Halbwachs, M. (2004) Los marcos sociales de la memoria. Barcelona: Anthropos.

Instituto Estadual Do Patrimônio Histórico E Artístico De Minas Gerais (IEPHA) (2014). Relatório de Atividades IEPHA/MG. 2011-2014. Belo Horizonte: IEPHA/MG.

KüHL, B. M. (1998). Arquitetura do ferro e arquitetura ferroviária em São Paulo: reflexões sobre a sua preservação. São Paulo; Ateliê Editorial, FAPESP.

Martyre, S. (1975). Companhia Estrada de Ferro Oeste de Minas. São Paulo: SBF.

Meneses, U. T. B. (1994). Do teatro da memória ao laboratório da História: a exposição museológica e o conhecimento histórico. Anais do Museu Paulista: História e Cultura Material, São Paulo, 2 (1), pp. 9-42, jan. ISSN 1982-0267. Recuperado de: <http://www.revistas.usp.br/anaismp/article/view/5289>.

Morais, S. S. (1999-2000) Preservação do Complexo Ferroviário de São João del Rey, Boletim Informativo da Associação Brasileira de Conservadores-Restauradores de Bens Culturais, Rio de Janeiro, Dez./Jan./Fev., pp. 4-5.

Prefeitura Municipal De Ribeirão Vermelho. Site institucional. Recuperado de: $<$ www.ribeiraovermelho.mg.gov.br>.

Rodrigues da Silva, R. A. (2014a). Patrimônio industrial, memória e identidade social: quem são as Rotundas Ferroviárias? In: 3ํ. Congresso Internacional Interdisciplinar em Sociais e Humanidades. Salvador: CONINTER3, 16, pp.355-367.

Rodrigues da Silva, R. A. (2014b). Patrimônio ferroviário brasileiro: da inclusão à exclusão de uma paisagem cultural. In: $3^{\circ}$ Colóquio Ibero-Americano. Paisagem Cultural, Patrimônio e Projeto - Desafios e Perspectivas. Belo Horizonte: IEDS.

Rodrigues da Silva, R. A. (2015). As rotundas ferroviárias: uma identidade cultural do patrimônio industrial brasileiro In: Colección Los Ojos de la Memoria: Espacios industriales abandonados: gestión del patrimonio y medio ambiente. Gijón: CICEES, 18, pp. 441-448.

Santos, M. S. dos. (1998). Sobre a autonomia das novas identidades coletivas: alguns problemas teóricos, Revista Brasileira de Ciências Sociais, 13(38).

Tartarini, J. D. (2001). Arquitectura ferroviária. Buenos Aires; Colihue, CEDODAL. 